\title{
Doğa ve İnsan İlişkisinde Kuş Evleri
}

Arş. Gör. Hayrun Nisa Kuruçay

Arş. Gör. Emre Kuruçay

\section{Özet}

Modern şehirlerin kuruluşundan bu yana geçen zaman, şehirlerin insan üzerindeki etkisini gösterdi; git gide artan doğa - insan karșıtlığı. Bu yapay sonucun fark edilmesiyle, insanın bir kentli olarak var oluşundansa doğanın bir parçası olduğuyla ilgili söylemler önemle gündeme gelmeye başladı. Her ne kadar bu söylemlerin kabul görmesi oldukça popüler olmasından kaynaklansa da gerçekle daha ilişkili olması nedeniyle, insan ve doğanın kesişim noktalarııı artıran tasarım arayışları başladı. Bu arayıșların en belirgin olanlarından biri, ölçeklerive doğa ile ilișkisi dolayısıyla, kuș evleridir. Bu çalışmada incelenen son on yıla ait kuş evi tasarımları bu açıklamayı destekler. İncelenen örnekler. tarihinde doğayla daha samimi iliskiler kuran insanların kus evlerine bir övgüden ziyade, doğaya dönmeye çalışan günümüz insanının tasarımlarını incelemek ve anlamak adına seçilmiștir. Bunu dönmeye çalışan günümüz insanının tasarımlarını incelemek ve anlamak adına seçilmiştir. Bunu
yaparken örnekler form ve tasarım anlayışlarıla birlikte irdelenmiştir. Ayrıca kuş evlerinin hem tarihteki hem de günümüzdeki örneklerine bakıldı̆̆ında gerek siluet gerekse barınma, sığınma gibi fonksiyonlarla mimari tasarım ile yakından ilişkili olması da makalenin önemli bir konusudur.

Anahtar Kelimler: Tasarım, Doğa, Kuş, Kuş Evi, Yuva

\section{BIRDHOUSES IN NATURE AND HUMAN RELATIONSHIP}

\section{Abstract}

In the course of time, since the founding of modern cities, indicating the influence of cities on people: the increasing nature-human opposition. With the realization of this artificial result, discourses about the fact that human beings are a part of nature rather than existence as a citizen have started to come to the fore. Although the acceptance of these discourses is due to their popularity mostly related to reality, the search for a design that increases the intersection of human and nature has begun. One of the most obvious of these quests is birdhouses, due to their scale and relationship with nature. The birdhouse designs of the last decade examined in this paper support this explanation. The examples examined, rather than a tribute to the birdhouses of people who have this explanation. The examples examined, rather than a tribute to the birchouses of people who have established more intimate relationships with nature in their history, were chosen in order to examine were examined together with their form and design concepts. In addition, the fact that birdhouses are closely related to architectural design, both with silhouette and functions such as bird sanctuary and shelter, is an important subject of the article.

Keywords: Design, Nature, Bird, Birdhouse, Nest 


\section{Giriş}

Kuşlar kendi doğalarına bırakıldıklarında, cinslerine göre kendi yuvasını kurabilen canlılardır. Ancak ortak kullandığımız doğada yalnızca kuşlara değil tüm canlılara ve yaşam alanlarına, kimi zaman bilerek kimi zamanda dikkatsizce, zarar verilmektedir. Özellikle endüstrileşme dönemi öncesi şehirleri için bir şenlik, o dönemin insanı içinsetabiat duygusunun ifadelerinden olan kuşlar; endüstrileşme sonrasının modern şehirlerinde kendilerine yer bulamamıştır. Makine metaforunun etkisindeki modern evin saçaksız çatıları insanların doğaya, doğanın da insanlara yabancılaşmasının adımlarından biridir.

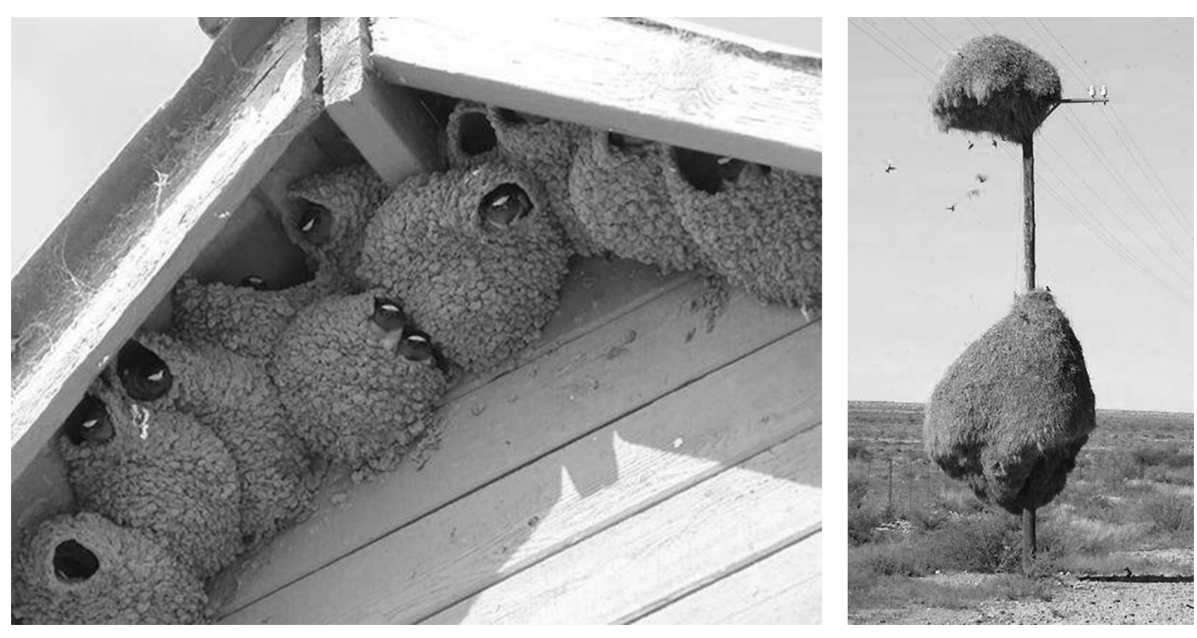

Görsel I. Kuşların kendiğilinden kurdukları yuvala

Almayı düşünmeden vermeyi amaç edinen, endüstrileşme öncesi insanların doğa ile ilişkisi daha samimidir (Oruç, 2009).Bu anlamda, Osmanlı toplumuna baktığımızda birçok canlıyı düşünerek yapılan evler, hastaneler ve benzeri yapılar bulmak mümkündür. Özellikle kuşların barınacakları bir kovuk ya da delikle onları korumayı görev edinseler de zaman içinde bu Osmanlı'da bir tutku halini almıştır(Barışta, 2000).Kimi zaman kuşların fiziksel özellikleri, kimi zaman yer çekimine karşı koyuşları, kimi zamansa göçleri insanoğlunu heyecanlandırmakta, harekete geçirmektedir. Bunun paralelinde ise kuş kovukları da kuş evlerine, saraylarına ve hatta camilerine dönüşmektedir (Bektaş, 2003). Yuvalar genellikle bir binayla birlikte yapılmakta ve binanın dönemsel özelliklerini taşımaktadır. O dönemlerde yapılan kuş evlerinin bu özelliği sayesinde dönemlerin sivil mimari örnekleri günümüze taşınmakta ve böylece bugün artık olmayan sivil mimari örneklerin dönemsel değişimleri incelenebilmektedir.
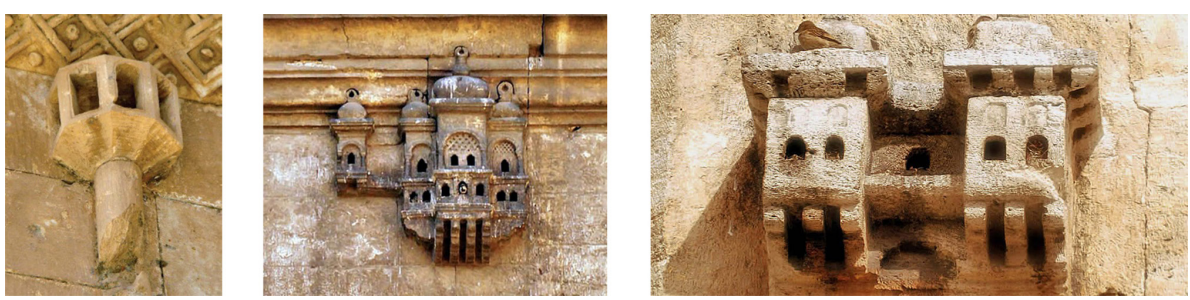

Görsel 2. (Soldan sağa) I-İshak Paşa sarayı-Doğu Bayezid-18. Yy, I8. yüzyılda inşa edilmesine rağmen, Osmanlı mimari gelişimi dışında kalan Doğu Bayezid'de bulunan arkaik mimari özellikleri taşıyan kuş evi. 2- Ayazma Cami - Üsküdar - 18. Yy, Barok Mimari özellikleri taşıyan kuş evi. 3- Bali Paşa Cami - Fatih - 15. Yy, KlasikOsmanlı mimarisi.

Kuş evleri yalnızca Osmanlı ile sınırlı kalmamasına rağmen, Osmanlı'da olduğu kadar da yaygın değildir. Özellikle Arap ve Acem illerinde de yerel malzeme ile yapılmış, alternatif mimariye örnek verilebilecek nitelikte güvercinlik olarak anılan kuş evleribulunur. Bulundukları kentlerin önemli yerel değerleri olan bu yapılar 20. yüzyılın ikinci yarııında önemini yitirse de önceleri fonksiyonel olarak da çeşitliamaçlara hizmet eden önemli yapılardandır (Amirkhani, Okhoyat ve Zamani, 2010).Bu coğrafyadakilere benzeyen yapılara bölgenin kendine has kayalıklarına adeta işlenmiş olarak Kapadokya Bölgesi'nde de rastlanır (19. yy)(Erman, 2014).
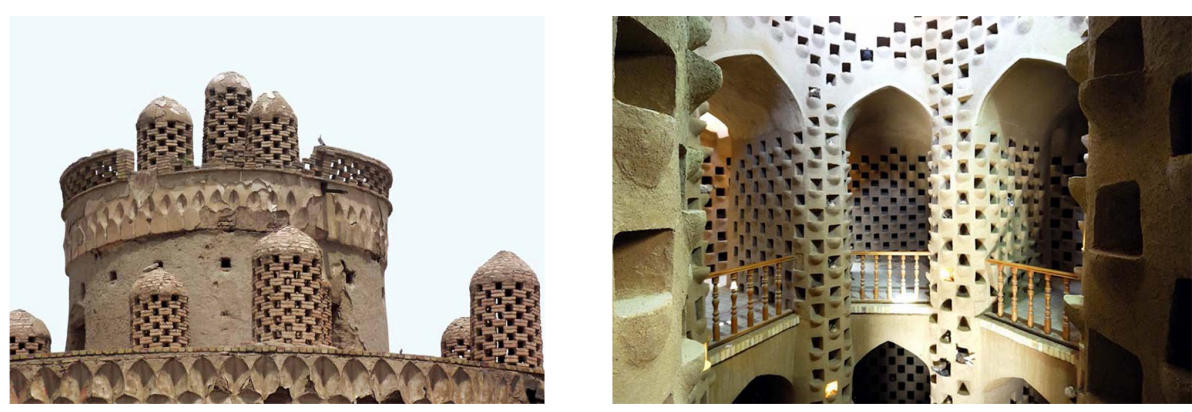

Görsel 3. İran'da bulunan güvercin haneler - İsfahan

\section{Kuş Evi Tasarımına Dair}

Osmanlı dönemindeki kuş evleri, duvar içinde açılmış tek boşluktan ya da oyularak işlenerek duvara eklenen taş veya tuğla malzemeli yapılardır (Çalışkan ve Koç, 2019). Ilk bahsedilen kus evleri, yapım esnasında kullanılan malzemelerdeki kırık köşelerin dahi ustalar tarafından bir kuş 
evine dönüştürüldüğ̈ü basit kovuklardır. ìkinci grup kuş evleri ise toplumsal hassasiyetlere göre şekillenmiş, dönemin mimarisini taklit eden tasarımlar olarak şekillenmiştir. Bir kuş evinin nasıl olması gerektiğine dair,tasarımcılara ait fikirler yakın zamana kadar çok üzerinde durulan bir konu olmamışır ta ki doğaya yönelik kimi araştırmaların olumsuz sinyal vermesine ve 21 . yüzyıl insanının doğaya karşı bilinçlenmesine dek. Bu anlamda genellikle geri dönüşümlü, doğaya zarar vermeyen malzeme kullanımları, çevrenin doğal dengesine karşı yapay müdahalelerin azalmasına yönelik tavırların yaygınlaşması gibi çevreci söylemlerin artışı, insanları bir şeyler aramaya itmiştir. "Insan merkezcil" bir yaşamın aslında insanı, "çevre merkezcil" bir yaşam kadar mutlu edemediği ortadadır ve bu nedenle "derin ekoloji" olarak isimlendirilen yeni birtakım faaliyetlerle, aslında doğanın parçası olan insan ile diğer canlıların kentteki çok boyutlu birliktelikleri irdelenip, çözümler üretilmeye başlamıştır (Ürgüplü, 2013).

Yakın zamana kadar belki de kuşların özgürlüğüne bir müdahale gibi görüldüğü için pek ele alınmayan kuş evleri, bu yeni gelişmelerle birlikte tekrar değerlendirilerek önemli bir tasarım nesnesi haline gelmiştir.

Kuş evleri tarihteki örneklerinde olduğu gibi günümüzdeki örnekleriyle de gerek silueti gerekse barınma, sığınma gibi fonksiyonlarıyla mimari tasarım ürünlerine doğal olarak gönderme yapmaktadır. Bunun yanında günümüzde başka biçimlere de göndermeler yapan örnekleri de oldukça fazladır. Bu anlamda tasarım anlayışı açısından postmodern örnekler oldukça yaygın olmakla beraber rasyonel örneklere de rastlanır. Bunlara ek olarak hazı bulunmuş nesnelerden yapılan kuş evleri de malzemenin kolayca geri dönüşümünü sağlaması nedeniyle genellikle halk arasında yaygındır.

"Bir kuş evi nasıl olmalıdır?" sorusunun artık bir tasarım problemi halini aldığını gösteren iyi örneklerden biri, Milano Triennale'ine katılan bir grup tasarımcının bu soruyu çıkıs noktası almasıdır. Bahsi geçen tasarımcılar Roberto Giacomucci tarafından koordine edilen 24 kişilik bir gruptan oluşmaktadır. Grup, 2017 yılında Milano Triennale'ine katılarak; çeşitli renk, biçim denemeleri ve farklı yöntemlerle tasarladıkları kus evlerini sergilemişlerdir. Bu sergi,Roberto Giacomucci (2017) tarafından bir deney olarak görülmektedir. Aslen böylesine mimari form ve fonksiyonla ilişkili olan kuş evleri, pratikte, mimari tasarım için de bir deneme sahası olarak görülebilir.

Aşağıda çalışmanın tüm ürünleri, tasarımcılarıyla birlikte verilmiştir. Bunlarınbirçoğutarih dışı birtakım nesnelere gönderme yapan postmoderntasarımlardır.5, 13 ve 23 numaralı çalışmalar isetasarımı görmeyen bir kişiye kolayca tarif edilebileceğinden (Özer,2019), postmodern değil rasyonel tasarımlar olarak tasniflenebilir.

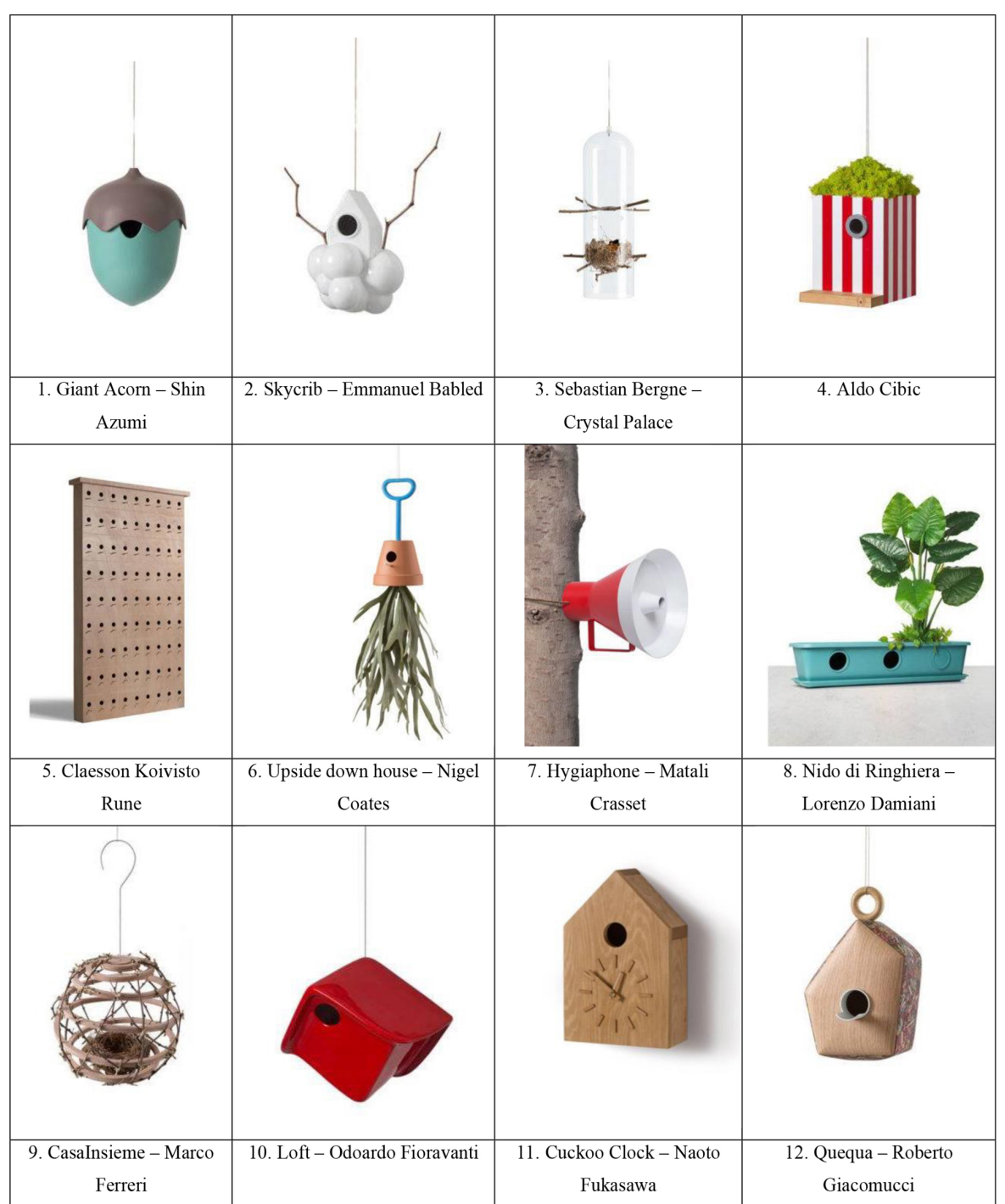

Tablo I. House of Birds - WhereDesignersMakeNest, Triennaledi Milano 


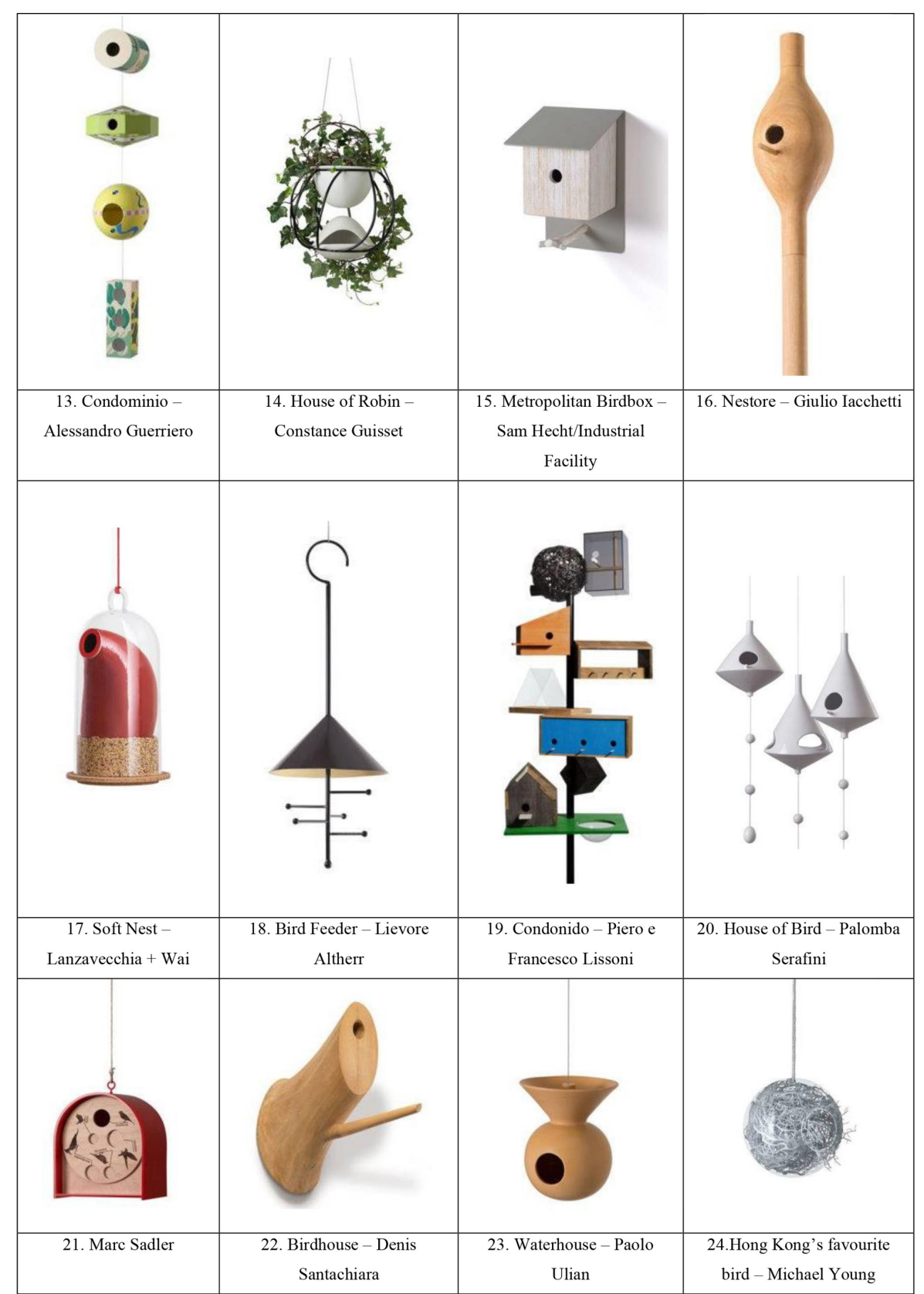

Tablo I. House of Birds - WhereDesignersMakeNest, Triennaledi Milano (Devamı)
Görüldüğü üzere bir kuş evi, genellikle kuşun barındığı ana mekân ve bu mekâna girmeden önce önünde durabileceği,yuvaya girmeye veya yuvadan çıkmaya hazırlık mekânı olanbir nevi arayüze ihtiyaç duyar. Bu veriler göz önünde bulundurularak aşağıda bazı yeni kuş evi tasarımları; form vetasarım anlayışları açısından irdelenmiştir.

Bahsedilen form anlayışları, MSGSÜ Mimarlık Tarihi Yüksek Lisans Programı'nda Filiz Özer'in yürüttüğü “Endüstri Tasarımın Gelişmesinde Mimarlık ve Plastik Sanatların Etkisi" dersinde işlendiği sekliyle irdelenmiștir. Özer (2019), tasarım nesnesinin küçük parçaların bir araya gelmesi ile oluşmasını "Kristalize Form", tüm parçaların kapalı bir bütün oluşturmasıyla meydana gelişine "Entegral Form", aşırı bir yayılım veya büyüme-uzama göstermesi ile oluşmasına "Enerjik Form", plastik nitelikli heykelsi bütünlükte olmasını da "Organik Form" olarak tanımlanmasını desteklemektedir. Biçimlerin Yaşamı adlı kitabında Focillon (2015) biçimlerin yani formların uzun süreli geçirdikleri evreleri;arkaik doğuş, klasikleşme, baroklaşma ve biçimin ölümü olarak sınıflandırır. Bu, belli bir formun uzun zamana yayılabilecek bir öyküsü olduğundan bu çalışmada ilk sınıflandırma çeşidi kullanılmıştır.
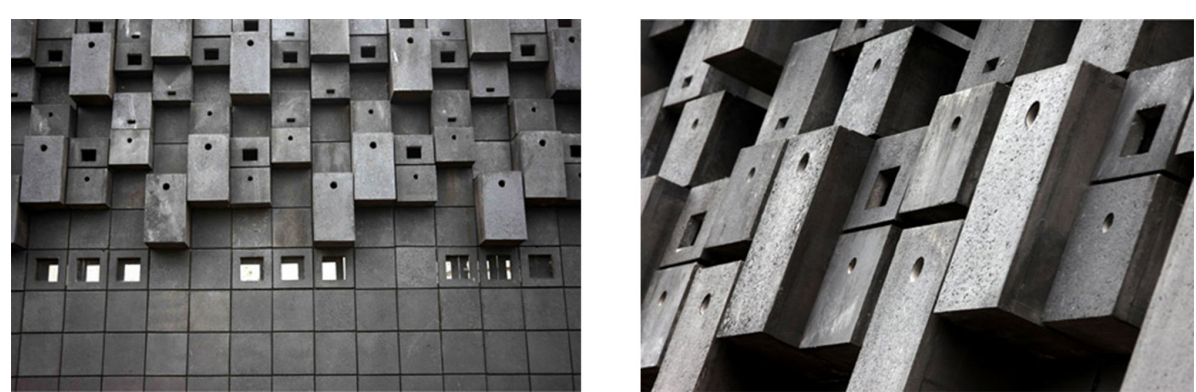

Görsel 4. Animal Wall by Gitta Gschwendtner

Londralı tasarımcı Gitta Gschwendtner tarafından tasarlanan Görsel 4'teki "Animal Wall" 50m uzunluğundadır. Tasarım bir konut grubunu yakından geçen bir nehirden ayırmaktadır. Duvardaki delikler farklı türde kuşlar için farklı boyutlarda tasarlanmıştır (Etherington, 2009).

Kuş evleri, 50 m'lik bir duvar gibi, oldukça genişlemiş ölçülerde olduğu için formu enerjiktir.Ayrıca formlar, tam dikdörtgenlerden oluştuğu için, tasarım anlayışı açısından rasyoneldir. 

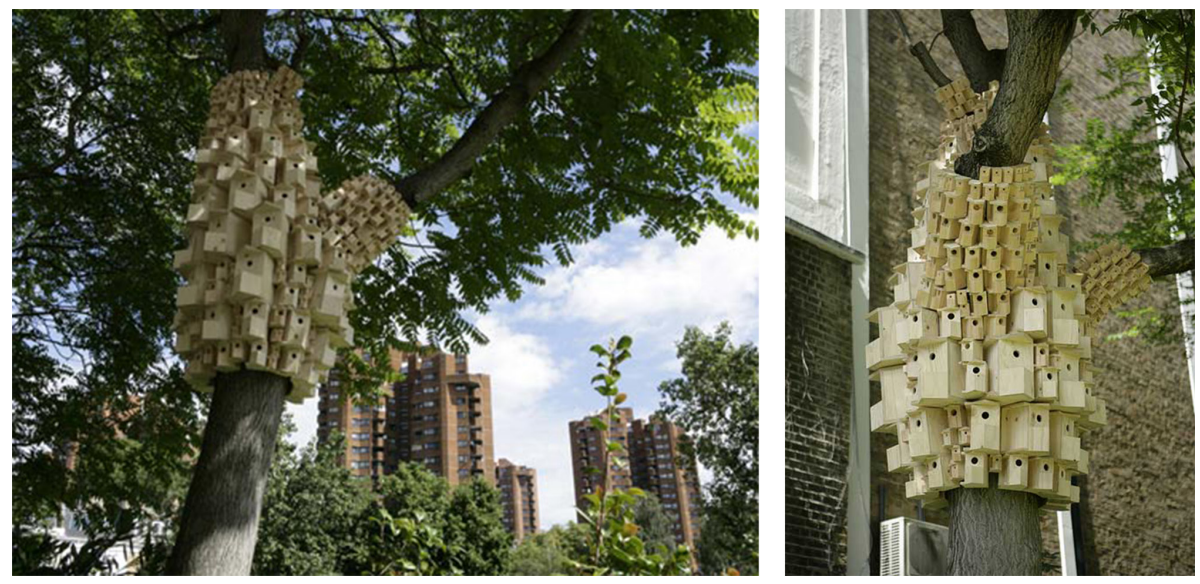

Görsel 5. Spontaneous City in the Tree of Heaven By London Fieldworks

London Fieldworks tarafından tasarlanan Görsel 5'teki örnek, şehirdeki yapıları örnek alarak onlarla uyumlu tasarlanmıstır. Sehrin beklenmedik yerlerinde insanların karşısına çıkan tasarımlar birer heykeli andırmaktadır. Form kategorisi ve tasarım üslubu açısından Görsel 4'teki ile aynı olan bu tasarım bize, tasarımcıların tekil birim tasarımı kadar hatta belki de daha çok eğildikleri noktanın, farklı birimlerin bir araya getiriliş şekli olduğunu gösteriyor (Mills,2010).

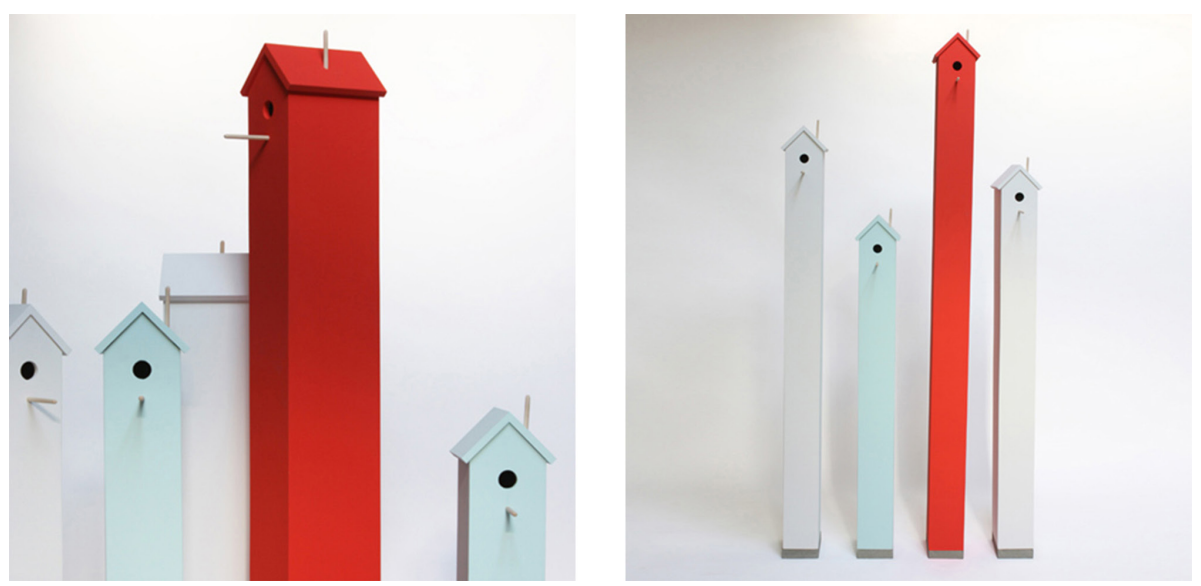

Görsel 6. Attic by Studio Chad Wright
Görsel 6'daki Amerikalı tasarımcı Chad Wright, temel kus evi formunun boyutlarında oluşturduğu aşırılıklarla yeni bir form meydana getirmiştir. Bu nedenle rasyonel tasarım anlayışılla tasarlanan bu kus evi,entegre form kategorisinde gibi görülse de enerjik form kategorisi kapsamında değerlendirilmek için daha uygundur (Nazemi, 2011).
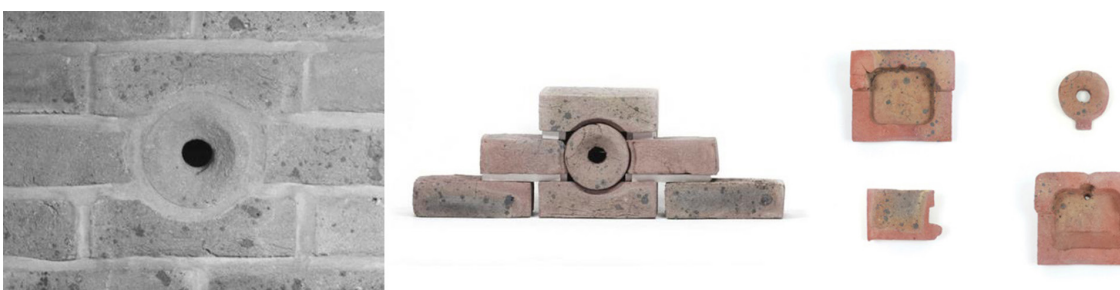

Görsel 7. Bird Nesting Bricks by Aaron Dunkerton

Tasarımcı Aaron Dunkerton, nesli tükenmekte olan kuşların binalarda ya da bahçe duvarlarında yuva yapması için, bazı Osmanlı Kuş evlerinde benzeyen bir tasarım yapmışıı. Birbirlerini tamamlayan şekillerde bir araya gelen tuğlaların, herhangi bir duvar örgüsüne kolayca eklemlenmesi amaçlanmıştır. Tasarım tam uyumlu parçaların oluşturduğu bir bütün olduğu için entegral form kategorisine girmekte ve rasyonel tasarım anlatışının özelliklerini göstermektedir (Andrews, 2013).
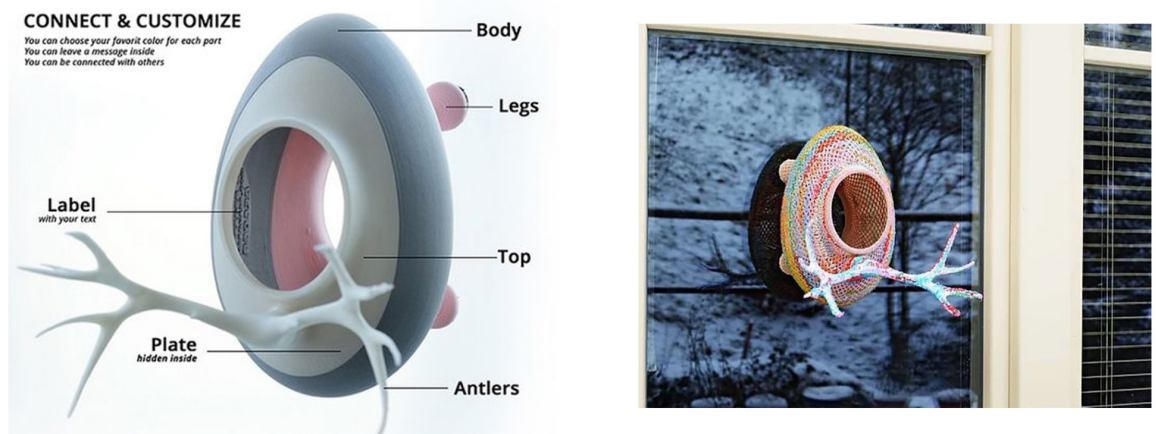

Görsel 8. 3D Printed Nest

Görsel 8. 3D baskı araçları için dijital olarak hazırlanmış bir dosyanın satışı ile alıcıların kendi baskı cihazlarında 3D olarak ürettikleri bir tasarımdır Güncel tasarım ve ticaret anlayışlarına oldukça uygun olan bu kuş evi ile dünya çapında bir kuş besleyicileri ağı oluşturmak hedeflenmiştir (Hazzard To ve Hazzard Tr, 2016). 
Tasarım, giriş uzantısı geyik boynuzuna ya da ağaç dallarına gönderme yaptığı için postmodern tasarım anlatışındadır. Form kategorisi olarak ise kuş evleri için fonksiyonel olan giris uzantısı ve ana mekân birlikte değerlendirildiği de göz önünde bulundurularak, tasarım organik form kategorisindedir.
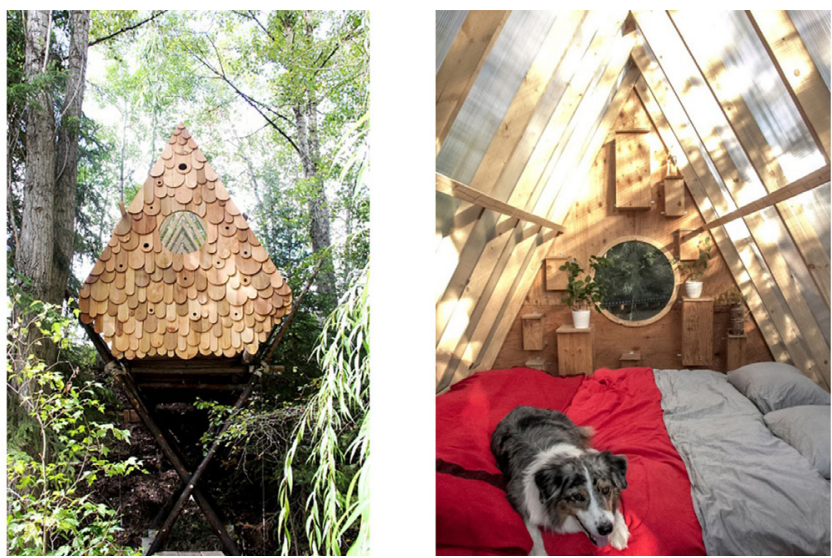

Görsel 9. Birds and humans share wooden treehouse in western Canada by Studio North

Yukarıdaki tasarım, Kanada'da "Studio North" adlı bir tasarım grubu tarafından, insanlar ve kuşların ortak kullandığı bir ağaç ev olarak tasarlamıştır. Kamp için alana gelen insanların da öndeki kuş kutularında barındığı gibi tesadüfi bir şekilde barınmaları amacını taşımaktadır (McKnight,2017).

Tasarımın kuşlar için olan bölümü çok sayıda yüzeyin birleşmesinden oluştuğu ve yine kuşlar için ayrılan bölüm çok sayıda kutudan oluştuğu için tasarımı kristalize form kategorisinde sayabiliriz. Ancak tasarımın bütünü entegral form kategorisine dâhildir. Aynı zamanda, kuş evleri, dikdörtgen kutulardan oluştuğu ve kuşların girmesi için açılan fonksiyonel delik yuvarlak olduğu için de tasarımı rasyonel olarak değerlendirebiliriz.
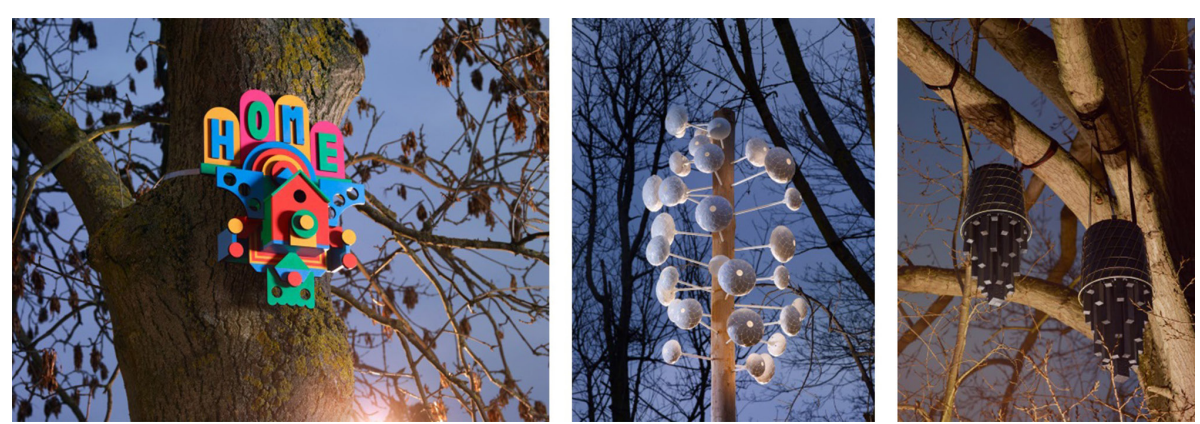

Görsel 10. IKEA upcyclesfurnitureintocolourful Wildhomesfor Wildlife
Yukarıdaki tasarımlar, IKEAmağazalarının bir reklamı olarak, Stüdyo Weave'den mimarlar ve tasarımcı Adam NathanielFurmantarafından tasarlanmıştır. Kus evleri, arı ve böcek yuvalarından olusan bu koleksiyon, IKEA mobilyalarının geri dönüşüm materyallerinden, “artık tüm yeni komşularımız evin tadını çıkarabilir" sloganıyla tasarlanmıştır.Tasarımlar farklı kuş türlerini çekmeyi hedeflemektedir (Aouf, 2019).

Soldan sağa doğru; postmodern, rasyonel ve tekrar rasyonel tasarım anlayışıyla tasarlanan kuş evlerinin form kategorileri de yine soldan sağa; kristalize form, kristalize ve entegral formdadır.
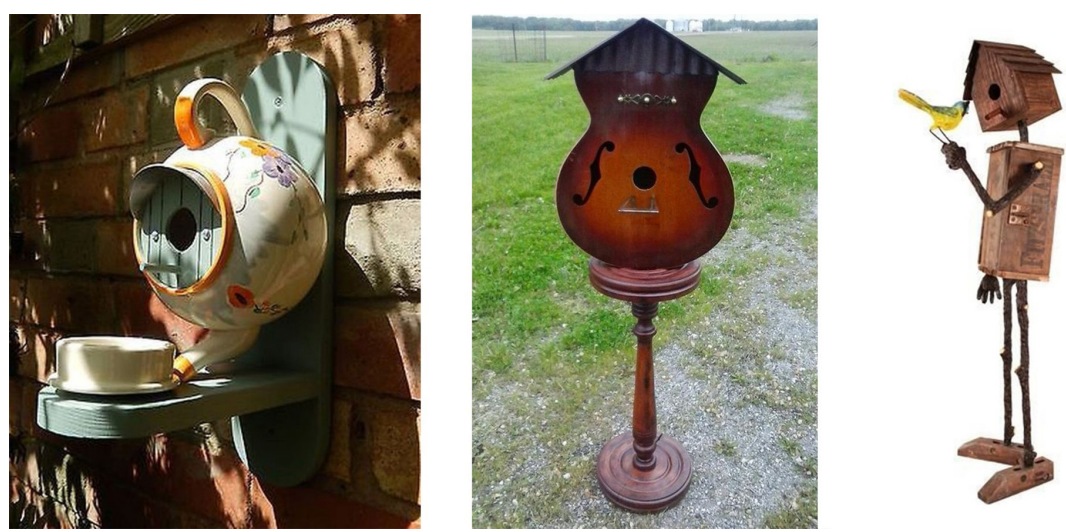

Görsel I I. Hazır bulunmuş nesnelerle kuş evi tasarımı

Hazır bulunmuş nesne ile yapılan kuş evi tasarımlarının büyük bir çoğunluğu postmodern tasarım anlayışındadır. Yukarıdaki üç örneği;tasarım anlayışı olarak postmodern, form kategorisi olarak da kristalize form olarak sınıflandırabiliriz. Gündemde olan geri atık olarak değerlendirilen malzemelerin geri dönüşümü ile ilgili yönelim, hazır bulunmuş nesneler ile bu tarz tasarımların yapılmasını, özellikle halk arasında, artırmaktadır.

\section{Sonuç}

Günümüzde farklı nedenlerle; ama en çok da yapay ve sevgisiz müdahalelerle doğa, giderek insanların yaşam alanlarından çekilmekte.Buna karşıncanlılar hayata daha güçlü bağlanma, uyum sağlama yollarını deniyorlar. Örneğin şehrin gürültüsünde diğerlerini arayan bir kuş, artık daha yüksek sesler ötmeye başlıyor, tıpkı aynıkaosta sesini duyurmak isteyen insanlar gibi.Ama belki de yükselen bu seslerle canlılar kendilerini insana duyurmayı başardı. Günümüz insanı artık doğayla barışma yollarını aramakta.

Doğayla ilgili farkındalığın arttığı son 10 hatta 20 yıllık süreçte, ne gibi çö- 
zümler üretilebileceği araştırlıyor. Bu kapsamda değerlendirdiğimiz üzere kuş evleri, geçmişteki şehir neşesini geri getirmek üzere bir tasarım nesnesi olarak görülmeye başlandı. IIlk örneklerini yüzyıllar önce gördüğümmüz kuş evleri,insanın doğaya bir teması. Ancak uzun yıllardır doğa ile pek de ilgilenmeyen insan, gerçekten eski yıllardaki gibi gerçek duygularla mı bu konu üzerine eğilmeye başlandı, yoksa gizli bir menfaat dürtüsüyle mi, daha tam olarak anlayamıyoruz.

Gerçek şu ki, kuş evleri artık bir tasarım sorunudur. Bu ürünle ilgili çalışmalar, mimarlar için mimari formlar ile oldukça ilişkili olduğu için heyecan vericidir. Kuş evleri, özellikle öğrenciler için deneme fırsatı olarak değerlendirilebilir. Profesyoneller içinse neredeyse bir sosyal sorumluluk sahasına dönüşmüş değerli bir alan halini almış durumdadır.

Yeni bir tasarım nesnesi olarak ele aldığımız kuş evleri için ya tekil birim tasarımından ya da bir birimin farkı şekillerde bir araya getirilişlerinden bahsedilebilir. Bu anlamda yukarıda incelendiği üzere; kristalize, entegral, enerjik ve organik formlarda kuş evleri vardır. Ancak bir modülün faklı şekillerde bir araya gelmesiyle oluşan kuş evleri tasarımcıların tasarım yeteneklerini ortaya koyma açısından önemli olanaklar tanıdığı için kristalize, günümüz bilişim ve kalıp teknolojilerinin gelişmesiyle birlikte küçük ölçekli bir deneme ortamı oluştuğu için de organik formlu tasarımlara günümüzde daha çok rastlanmaktadır. Tasarım anlayıșı açısında ise kuş evleri genellikle, postmodern ya da rasyonel tasarımlardan oluşur. Kuş evleri; mimar, seramik sanatçısı, endüstri ürünleri tasarımcısı gibi uzmanlık alanlarının ve malzeme seçimlerinin çeşitlenmesiyle oldukça farkılıaşabilir. 


\section{Kaynakça}

Amirkhani A.,Okhoyat, H., Zamani, E. (2010). "Ancient Pigeon Houses: Remarkable Example of the Asian Culture Crystallized in the Architecture of Iran and Central Anatolia."Asian Culture and History, 2(2), 45-57

Bektaş, C. (2003). Kuş Evleri. İstanbul: Literatür Yayıncılık

Çalışkan, C. I., Koç, E. (2019). “Kuşevleri ve 3 Boyutlu Baskı Yöntemi ile Üretimi”, FSM illmi Araştırmalar İnsan ve Toplum Bilimleri Dergisi, I3(I), 167-I85

Erman, D. O. (20I4). "Bird Houses in Turkish Culture and Contemporary Applications", Procedia - Social and Behavioral Sciences I22, 306-31।

Focillon, H. (20I5). Biçimlerin yaşamı. (Çev. A. Tümertekin). İstanbul:Janus Yayıncılık

Özer, F. (20।9). Endüstri Tasarımııın Gelişimine Mimarlık ve Plastik Sanatların Etkileri Ders Notları, MSGSÜ Fen Bilimleri Enstitüsü, İstanbul.

Şölenay, E., Çelikoğlu, Ö. (20I2) “Bir Malzeme Olarak Seramiğin Kullanması”, Sanat ve Tasarım Dergisi, 2(2), 4I-5

Ürgüplü, G. (20I3). Derin Ekoloji Bağlamında Kentte Sokak Hayvanlarıyla Birlikte Yaşamak Olgusunun Incelenmesi, Yayınlanmamış Yüksek Lisans Tezi, iTÜ Fen Bilimleri Enstitüsü, İstanbul.

Barışta, H.Ö. (2000).Osmanlı İmparatorluğu Dönemi İstanbul'undan Kuşevleri. Ankara: T.C. Kültür Bakanlı̆̆ı Yayınları / 2528

\section{Internet Kaynakları}

Internet: House of Birds, WhereDesignersMakeNest (2017, Nisan). Web: https:// workshop.houseofbirds.it/en/ adresinden 17 Haziran 2020'de alınmıştır.

Internet:Etherington R. (2009, Ağustos). Animal Wall.Web:https://www.dezeen. com/2009/08/28/animal-wall-by-gitta-gschwendtner/adresinden 17 Haziran 2020'de alınmıştır.

Internet:Mills, J. (20I0, Eylül). Spontaneous City in theTree of

HeavenbyLondonFieldworks. Web:https://www.dezeen.com/2010/09/08/ spontaneous-city-in-the-tree-of-heavenby-london-fieldworks/adresinden 17 Haziran 2020 'de alınmıştır.

Internet:Nazemi, M. (201 I, Kasım).Attic. Webhttps://www.dezeen.com/20 I I/ I I/I8/ attic-by-studio-chad-wright/adresinden 17 Haziran 2020'de alınmıştır.

Internet: Andrews, K. (2013, Temmuz).Bird Nesting Bricks. Web:https:// www.dezeen.com/2013/07/16/bird-nesting-bricks-by-aaron-

dunkerton/\#: : text=Aaron\%20Dunkerton's\%20Bird\%20Nesting\%20 Bricks,a\%20small\%20clay\%20entrance\%20hole. adresinden 17 Haziran 2020'de alınmışıır.

Internet:3D PrintedBirdNestDesigns(2016). Web: https://3dstartpoint.com/3dprinted-bird-nest-designs/adresinden 17 Haziran 2020'de alınmıştır.

Internet: McKnight, J. (2017, Kasım). Birds and humans share wooden treehouse in western Canada. Web: https:/www.dezeen.com/2017/1 I/27/studio-north-birdhutwooden-treehouse-western-canada-camping-birds-humans/adresinden 17 Haziran 2020 'de alınmıştır.

Internet: Aouf, R. S. (2019, Mart). IKEA upcyclesfurnitureintocolourfulWildhomesfor Wildlife. Web:https://www.dezeen.com/2019/03/2I/wildhomes-for-wildlife-ikeadesign/adresinden 17 Haziran 2020'de alınmıştır.

İnternet: Oruç, S. (2009) Kuş evleri, almadan verebilmenin sembolü. http://www. trakus.org/kods_bird/pdf/22856.pdf

\section{Görsel Kaynaklar}

Görsel I:Kuşların kendiğilinden kurdukları yuvalar Web: https://tr.pinterest.com/ pin/434456695307772465/ adresinden 17 Haziran 2020'de alınmıştır.

Görsel2: I-İshak Paşa sarayı, 2- Ayazma Cami, 3- Bali Pașa Cami Web:https:// tr.pinterest.com/pin/43445669530777246I/ adresinden 17 Haziran 2020'de alınmıştır.

Görsel 3: İran'da bulunan güvercin haneler - İsfahan Web: https://tr.pinterest.com/ pin/434456695307772464/ adresinden 17 Haziran 2020'de alınmıştır.

Görsel 4: İnternet:Etherington R. (2009, Ağustos). Animal Wall.Web:https://www. dezeen.com/2009/08/28/animal-wall-by-gitta-gschwendtner/adresinden 17 Haziran 2020 'de alınmıştır. 
Görsel 5:Mills, J. (2010, Eylül). Spontaneous City in theTree of

HeavenbyLondonFieldworks. Web:https://www.dezeen.com/20 I0/09/08/

spontaneous-city-in-the-tree-of-heavenby-london-fieldworks/adresinden 17 Haziran 2020'de alınmıştır.

Görsel 6:Nazemi, M. (20II, Kasım).Attic. Webhttps://www.dezeen.

com/20 I I/ I I/ I8/attic-by-studio-chad-wright/adresinden 17 Haziran 2020'de alınmıştır.

Görsel 7:Internet:Andrews, K. (2013, Temmuz).Bird Nesting Bricks.

Web:https://www.dezeen.com/2013/07/16/bird-nesting-bricks-by-aaron-

dunkerton/\#: : text =Aaron\%20Dunkerton's\%20Bird\%20Nesting\%20

Bricks,a\%20small\%20clay\%20entrance\%20hole. adresinden I7 Haziran 2020'de

alınmıştır.

Görsel 8:3D PrintedBirdNestDesigns(2016). Web: https://3dstartpoint.com/3d-

printed-bird-nest-designs/adresinden 17 Haziran 2020'de alınmıştır.

Görsel 9:McKnight, J. (2017, Kasım). Birds and humans share wooden treehouse in western Canada. Web: https://www.dezeen.com/2017/1 I/27/studio-north-birdhutwooden-treehouse-western-canada-camping-birds-humans/adresinden 17 Haziran 2020'de alınmıştır.

Görsel I0: Aouf, R. S. (2019, Mart). IKEA

upcyclesfurnitureintocolourfulWildhomesfor Wildlife. Web:https://www.dezeen. com/2019/03/2I/wildhomes-for-wildlife-ikea-design/adresinden I7 Haziran 2020'de alınmıştır.

Görsel I I:Hazır bulunmuş nesnelerle kuş evi tasarımı. Web: https://tr.pinterest.com/ pin/434456695307772452/adresinden 17 Haziran 2020'de alınmıştır.

Tablo I: Gromari, A. (2017, Nisan). House of Birds, WhereDesignersMakeNest.

Web: https://workshop.houseofbirds.it/en/ adresinden 17 Haziran 2020'de alınmıștır 